\title{
Contribution of intraoperative electrical stimulations in surgery of low grade gliomas: a comparative study between two series without (1985-96) and with (1996-2003) functional mapping in the same institution
}

\author{
H Duffau, M Lopes, F Arthuis, A Bitar, J-P Sichez, R Van Effenterre, L Capelle
}

J Neurol Neurosurg Psychiatry 2005;76:845-851. doi: 10.1136/jnnp.2004.048520

See end of article for authors' affiliations

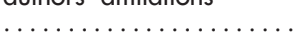

Correspondence to: Dr H Duffau, Service de Neurochirurgie, Hôpital de la Salpêtrière, 47-83 Bd de I'hôpital, 75651 Paris,

Cedex 13, France; hugues.duffau@ psl.ap-hop-paris.fr

Received 25 June 2004 Revised version received 27 August 2004

Accepted 10 October 2004
Objectives: Despite the growing use of intraoperative functional mapping in supratentorial low grade glioma (LGG) surgery, few studies have compared series of patients operated on without and with direct electrical stimulation (DES) by the same team. The present study compared the rate of LGG surgery performed in eloquent areas, the rate of postoperative sequelae, and the quality of resection during two consecutive periods in the same department-the first without and the second with the use of intraoperative electrophysiology.

Methods: Between 1985 and 1996, 100 patients harbouring a supratentorial LGG underwent surgery with no functional mapping (S1). Between 1996 and 2003, 122 patients were operated on in the same department for a supratentorial LGG using intraoperative cortico-subcortical DES (S2).

Results: Comparison between the two series showed that 35\% of LGGs were operated on in eloquent areas in $\mathrm{S} 1$ versus $62 \%$ in S2 ( $<<0.0001)$, with $17 \%$ severe permanent deficits in S1 versus $6.5 \%$ in S2 $(p<0.019)$. On postoperative MRI, 37\% of resections were subtotal and $6 \%$ total in $\mathrm{S} 1$ versus $50.8 \%$ and $25.4 \%$, respectively, in S2 ( $<<0.001)$. In both groups, survival was significantly related to the quality of resection.

Conclusions: The results of the present study allow, for the first time, quantification of the contribution of intraoperative DES in LGG resection. Indeed, the use of this method leads to the extension of indications of LGG surgery within eloquent areas; to a decrease in the risk of sequelae; and to improvement of the quality of tumour resection, with an impact on survival. in the past decade, a growing number of authors have investigated the use of intraoperative mapping with direct electrical stimulations (DES) during tumour surgery near or within eloquent areas. It has been claimed that this method allows minimising postoperative permanent deficit while maximising the quality of resection, particularly in infiltrative tumours such as low grade gliomas (LGGs). ${ }^{1-21}$ However, few comparative studies of two series of patients operated on without and with DES by the same team are available in the literature. ${ }^{22-24}$ Due to the parallel development of neurofunctional imaging techniques, the real role of intraoperative DES is still matter of debate, since this has not been statistically proven. ${ }^{25}$

In the present study, we compared three variables, the rate of LGG surgery performed in eloquent areas, the rate of postoperative sequelae, and quality of tumour resection, during two consecutive periods in the same department, the first without the use of intraoperative electrophysiology (1985-96) and the second with DES (1996-2003). The aim of our work was not to study the impact of surgery on the natural history of LGG, but to try to quantify the exact contribution of the DES in surgical resection of supratentorial LGGs.

\section{PATIENTS AND METHODS \\ Patients}

Between 1985 and 2003, 222 patients underwent surgical resection for a supratentorial LGG in our institution, without any previous therapy. Two consecutive periods were identified for the present study:
(1) from 1985 to October 1996, during which 100 patients were operated on without intraoperative electrophysiological mapping (retrospective study—series 1 (S1))

(2) from November 1996 to 2003, during which 122 patients were operated on with the use of DES (prospective study—series 2 (S2)).

A part of this experience has been described previously, with special attention to the detailed neurological outcome in series $2,{ }^{26}$ but no comparison was made with a surgical series in which intraoperative functional mapping was not done.

\section{Preoperative evaluation}

For both S1 and S2, we reviewed the presenting symptoms and preoperative neurological examination. Patients were classified in two groups:

- Group I: no or mild deficit, with Karnofsky Performance Status (KPS) ${ }^{27}$ score ranging between 80 and 100

- Group II: a severe deficit, which led to deterioration in the quality of life, with the patient unable to carry out normal activities (that is, KPS of 70 or less).

In both series, we analysed the topography of the tumour on a preoperative magnetic resonance (MR) image (Tlweighted and/or spoiled gradient images before and after

Abbreviations: DES, direct electrical stimulation; LGG, low grade glioma 
gadolinium enhancement in the three orthogonal planes and T2-weighted axial images. Fluid attenuated inversion recovery (FLAIR)-weighted axial images were taken in the last three years of series 2). The volume of the tumour was evaluated using the method proposed by Berger et al ${ }^{1}$ - that is, the product of the three largest diameters (two measured in the axial plane, the third measured in the sagittal plane, as we have previously reported ${ }^{28}$ ) divided by 2 . All tumours were graded functionally, relative to their location with respect to the eloquent brain, into two groups:

- tumours involving functional regions, according to the definition previously proposed by us $^{29}$-for example, motor cortex/supplementary motor area, somatosensory cortex, speech centres, visual cortex, insular lobe, internal capsule and deep grey nuclei

- tumours near or remote from eloquent areas and not invading these areas.

\section{Intraoperative technique}

In both series, we used the same surgical equipment (ultrasonic aspirator, bipolar coagulation, ultrasonography, operative microscope), except for the intraoperative functional mapping methods, which were not used in series 1 . In series 2, intraoperative real-time functional corticosubcortical mapping was performed during all the surgical procedures (motor mapping in 49 patients under general anaesthesia; sensorimotor and language mappings in 73 patients under local anaesthesia), using the technique of DES. We have described this technique in detail in previous reports, ${ }^{26}{ }^{30}{ }^{31}$ and it is based on the methodology described by Berger and Ojemann. ${ }^{32}{ }^{33}$ Our aim was first to track and preserve the eloquent structures at each moment and each site of resection to avoid postoperative sequelae, and second to continue LGG removal until functional areas were encountered so as not to interrupt the surgery prematurely, thus optimising the quality of resection.

Briefly, a $5 \mathrm{~mm}$ spaced tips bipolar electrode delivering a biphasic current (pulse frequency $60 \mathrm{~Hz}$, single pulse phase duration $1 \mathrm{~ms}$, amplitude from 6 to $18 \mathrm{~mA}$ under general anaesthesia and from 2 to $6 \mathrm{~mA}$ under local anaesthesia; Ojemann Cortical Stimulator 1, Radionics Inc, Burlington, MA) was applied on the brain. First, we performed electrical mapping at the cortical level before tumour removal to identify the essential eloquent sites that must be avoided and thus defined the superficial boundaries of the resection according to functional data. In addition to sensorimotor mapping, language tasks included systematic counting, naming, and reading. We also included a calculation task for lesions in the left angular and supramarginalis gyri, and repetition and/or semantic tasks for tumours within the left mid-posterior temporal lobe. Second, direct stimulations, with the same electrical parameters as those used at the cortical level, were continuously applied during glioma removal at the subcortical level to detect sensorimotor and/or language pathways, which represent the deep functional limits of resection.

It is important to note that even in series 2, we did not use an intraoperative neuronavigation system with incorporation of preoperative functional neuroimaging data. We preferred to use a real-time ultrasonography system, not only to delineate the tumour before its removal but also to control the residual amount during the resection.

\section{Postoperative evaluation}

Similar to the preoperative evaluation, postoperative neurological examination and KPS scoring were reviewed in both series after the third month following the surgery. We also performed at least one postoperative magnetic resonance imaging (MRI) scan in all patients to evaluate the quality of glioma removal. The classification reported by Berger et al ${ }^{1}$ was used (for example, "total" resection in case of no residual signal abnormality, "subtotal" resection in case of less than $10 \mathrm{ml}$ residue, and "partial" resection in case of more than $10 \mathrm{ml}$ residue). The volume of the residue was calculated with the same methods used preoperatively. Finally, mortality was evaluated in relation to the quality of resection in both groups.

\section{Statistics}

We used $\chi^{2}$ and Fisher's exact tests, except for the comparison of preoperative volumes of tumours: this analysis was performed using the non-parametric statistical tests, Wilcoxon's and Kruskal-Wallis.

\section{RESULTS}

The clinical, radiological, and surgical data of both series are summarised in table 1 .

\section{Clinical and radiological findings}

Seizures were the presenting symptoms in $95 \%$ of patients in both series. Clinically, the neurological examination was normal in 94 patients in S1 and 112 patients in S2. However, on the basis of the KPS scores, all patients from S1 and S2 were classed into group I-that is, with KPS between 80 and 100. In S1, 35 tumours involved functional areas (table 1 and fig lA) whereas in S2, 76 tumours were located within eloquent regions (table $\mathrm{l}$ and fig $2 \mathrm{~A})(\mathrm{p}<0.0001)$.

Of the tumours not invading eloquent areas, 29\% were near functional regions in S1 versus $32.7 \%$ in S2 (not significant), whereas $36 \%$ were remote from eloquent areas in $\mathrm{S} 1$ versus $5 \%$ in $\mathrm{S} 2(\mathrm{p}<0.0001)$. There was no significant difference between the groups with regard to preoperative tumour volumes $(\mathrm{p}=0.09)$ (see table 1 for details).

\section{Surgical findings}

In S2, intraoperative electrical mapping was used for the removal of all tumours located within and near eloquent areas (95\% of cases). Only six resections were performed without stimulation in this series. In all 116 surgeries with mapping, the stimulations allowed detection of the eloquent cortico-subcortical areas, systematically used as boundaries of the resection. However, the mean duration of surgery was longer in S2 (five $v$ three hours in S1) and the incidence of bone flap infection was $0.86 \%(1 / 116)$ in S2.

\section{Postoperative neurological results}

In S1, mortality was $2 \%$, and $17 \%$ with a severe permanent deficit were in group II (see table 1). In S2, there were no deaths, and $6.5 \%$ of patients with severe sequelae were in group II ( $\mathrm{p}<0.019$, two tailed test) (figs $1 \mathrm{~B}$ and $2 \mathrm{~B}$ ).

\section{Postoperative radiological results}

The difference between the quality of resections as evaluated on the postoperative control MRI in SI and S2 (see table 1) was statistically significant $(\mathrm{p}<0.001)$.

\section{Histological results}

On histopathological examination, a low grade glioma (WHO grade II) was diagnosed in all patients in both series. 


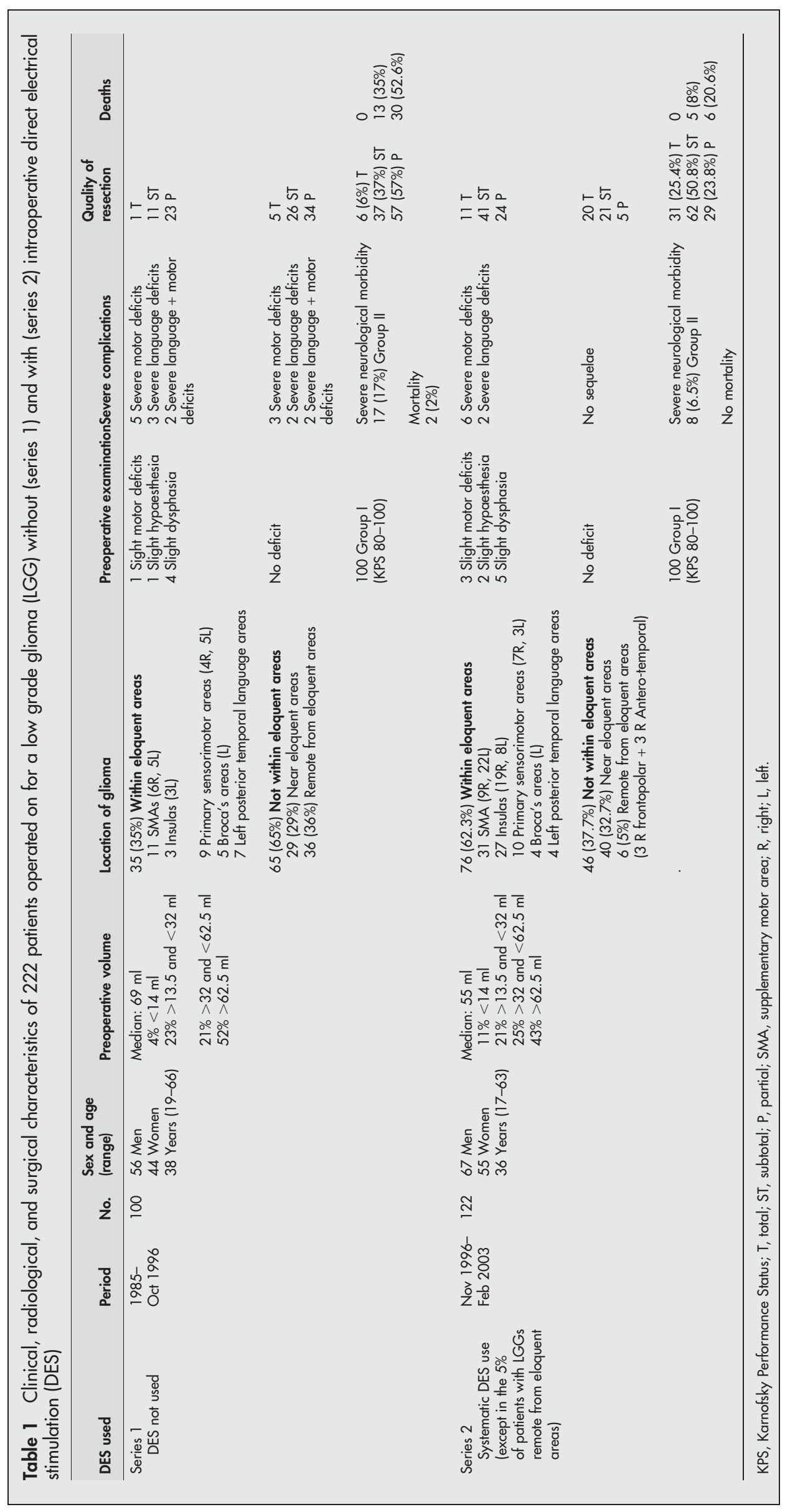



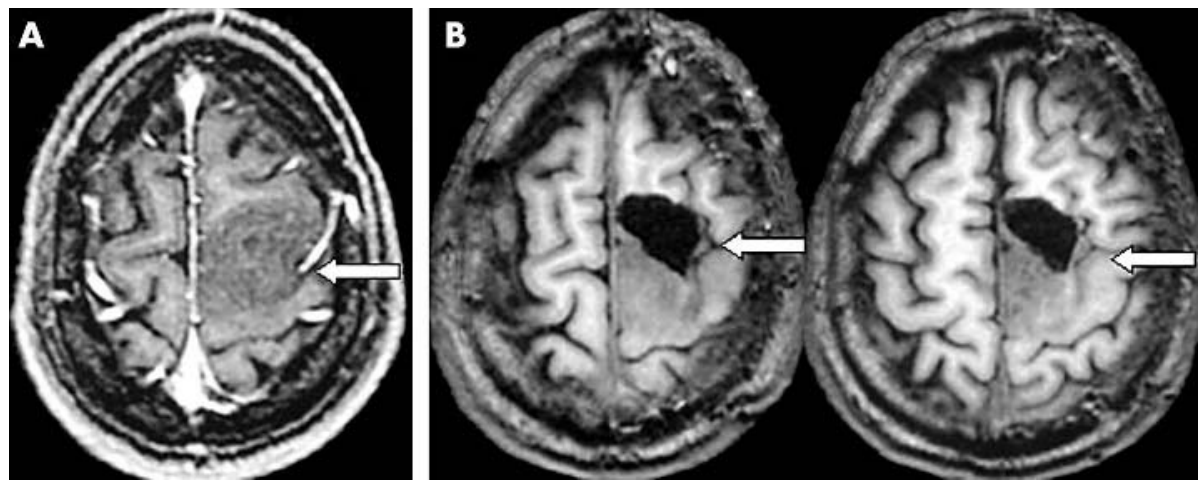

Figure 1 (A) Preoperative axial T1-weighted magnetic resonance imaging (MRI) scan, showing a left precentral low grade glioma invading the dominant superior frontal gyrus (series 1). (B) Postoperative axial T1-weighted MRI, after a surgery performed without intraoperative electrical mapping, showing the resection of the anterior part of the tumour, with a residue in contact with the primary motor area posteriorly. Arrow: precentral sulcus.

\section{Survival}

Based on the quality of resection, mortality in the two series was as follows.

- Series $1(p=0.04)$

- Partial resections: 30/57 (52.6\%), median follow up 72 months

- Subtotal resections: 13/37 (35\%), median follow up 87 months

- Complete resections: 0/6 (0\%), median follow up 75 months

- Series $2(\mathrm{p}=0.02)$

- Partial resections: 6/29 (20.6\%), median follow up 49 months

- Subtotal resections: 5/62 (8\%), median follow up 45 months

- Complete resections: 0/31 (0\%) median follow up 48 months

\section{DISCUSSION}

Recent literature reveals a more frequent use of intraoperative electrostimulation mapping during tumour surgery in eloquent brain areas, in particular for poorly demarcated lesions such as infiltrative LGGs. ${ }^{1-21}$ However, this method still remains controversial ${ }^{25}$ first, because of the alternative use of intraoperative electrophysiological monitoring techniques (evoked potentials) proposed by several authors ${ }^{24}{ }^{34}$; second, since it is necessary to perform the surgery under local anaesthesia to allow language mapping; and third, because of the recent development of neurofunctional imaging, which can be integrated into a neuronavigation system..$^{35}$

We believe that none of these criticisms is really well founded, since (a) evoked potentials do not allow the mapping of language and other cognitive functions, $(b)$ good tolerance of awake craniotomies has been well demonstrated, ${ }^{36-39}(c)$ neurofunctional imaging still lacks reliability, especially with regard to language mapping..$^{40}{ }^{41} \mathrm{In}$ fact, the real problem seems to be that only few studies have compared the results of surgery without and with the use of DES to evaluate the exact contribution of intraoperative electrostimulation. ${ }^{23}{ }^{24}$ Moreover, in these rare reports, the impact of DES and other methods, such as somatosensory evoked potentials and/or neuronavigation, has been evaluated together, ${ }^{23}{ }^{24}$ so it is difficult to assess the exact role of sole DES. Also, in these studies, intraoperative motor mapping was done only during tumour surgery within the central region and language mapping was not reported (except in rare series of dominant temporal lobectomies in epilepsy surgery, ${ }^{22}$ which present not exactly the same
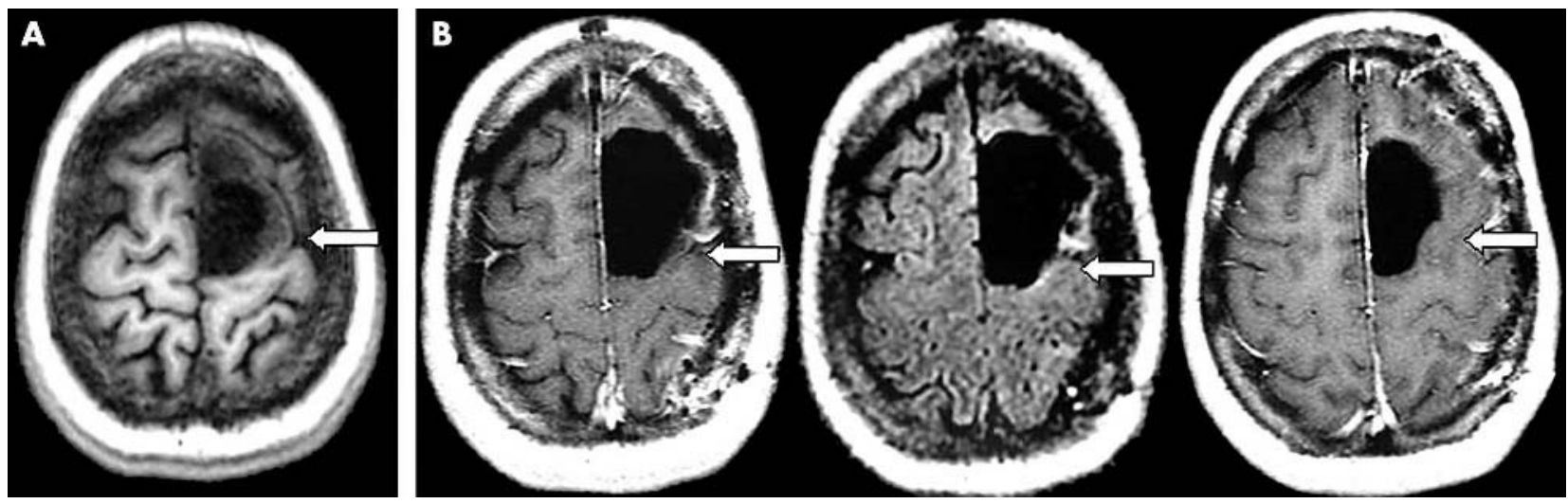

Figure 2 (A) Preoperative axial T1-weighted magnetic resonance imaging (MRI) scan, showing a similar left precentral low grade glioma invading the dominant superior frontal sulcus (series 2). (B) Postoperative axial T1-weighted and fluid attenuated inversion recovery (FLAIR)-weighted MRI, after a surgery performed with intraoperative electrical mapping, showing total resection of the tumour - the cavity coming into contact with the primary moto area posteriorly, identified by stimulations. Arrow: precentral sulcus. 
problem as in surgery for infiltrative cortico-subcortical gliomas). Finally, the tumours operated on have not all been the same, since the recent series of Reithmeier et al ${ }^{23}$ included not only low and high grade gliomas but also metastasis and meningiomas.

In the present study, we included a uniform consecutive sample to try to quantify the impact of DES during surgery of supratentorial LGGs, whatever their location, on (a) surgical indications, $(b)$ functional results, and $(c)$ quality of tumour resection.

\section{Extension of surgical indications}

Although surgery for infiltrating LGGs has been the subject of much controversy in the literature, ${ }^{42}$ a growing number of recent series have provided evidence for the favourable impact of resection on the natural history of this kind of lesion. ${ }^{43-45}$ Consequently, a patient who is not selected for resective surgery for technical reasons (for example, the location of the lesion) by a team which performs surgical resection for LGGs, if the tumour is in fact "operable", could potentially lose the chance of a favourable outcome.

In our experience, the definition of "operability" significantly changed between the first and the second series, since $62 \%$ of LGGs resected in S2 were located within eloquent areas, whereas only 35\% of LGGs involved functional regions in S1. Indeed, during the earlier period, there were patients in whom surgical resection was not considered an option: this was typically the case for insular LGGs, which were almost never removed in S1, being documented as "inoperable". However, we must point out the fact that the extension of surgical indications in S2 was partly due to the following confounding factors:

- evolution of the management of LGGs in the last decade, favouring aggressive treatment rather than a "wait and see" attitude, due to a better knowledge of the natural history -in particular with regard to the high risk of anaplastic transformation leading to death ${ }^{43-45}$

- development of preoperative neurofunctional imaging techniques, which allow better prediction of the individual functional surgical risk and improved surgical planning ${ }^{46}$

- improvement of the surgeon's experience, with a tendency towards "hyper-specialisation" in the second period, and thus a slight modification of the population of patients treated at our institution in S2 as reflected in the lower rate of LGG surgeries remote from eloquent regions.

Nevertheless, it seems that the use of intraoperative DES itself has had an actual impact on the modulation of our criteria of "operability". First, these methods of intraoperative mapping permit identification and preservation of the functional areas at each moment and each site of the resection. Thus, surgery within the eloquent area is not much more difficult than in "non-eloquent" regions, since the boundaries of the resection are defined in real time using objective and not subjective individual functional data. Second, DES has allowed us to understand better the pathophysiology of eloquent areas in which surgery was rare until recently-despite the fact that LGGs are often located in these areas, such as the insular lobe. ${ }^{47}{ }^{48}$ Indeed, an increase in the knowledge of the functional role of the critical brain regions using DES has permitted us to perform surgery in these structures with minimal risk. ${ }^{49-51}$ Third, DES allows the study of individual plasticity, ${ }^{53}$ a brain potential often described in functional compensation in patients harbouring an LGG, thus leading to an extension of the limits of resection in eloquent areas without induction of permanent deficit. ${ }^{29} 54$
Table 2 Permanent neurological deficit reported in the literature following surgery of gliomas performed using intraoperative electrical mapping

\begin{tabular}{|c|c|c|}
\hline Authors (year) & $\begin{array}{l}\text { No. of gliomas } \\
\text { (No. of LGGs, if } \\
\text { available) }\end{array}$ & $\begin{array}{l}\text { Permanent severe } \\
\text { postoperative deficits } \\
\text { No. of patients }(\%)\end{array}$ \\
\hline $\begin{array}{l}\text { Berger et al }(1994)^{1} \\
\text { Cukiert et al }(1995)^{2} \\
\text { Ebel et al }(2000)^{3} \\
\text { Ebeling et al }(1995)^{4} \\
\text { Eisner et al }(2002)^{5} \\
\text { Fandino et al }(1999)^{6} \\
\text { Fuyaka et al }(2001)^{7} \\
\text { Haglund et al }(1994)^{8} \\
\text { Krombach et al (1998) } \\
\text { Meyer et al }(2001)^{10} \\
\text { Nikas et al }(1998)^{11} \\
\text { Peraud et al }(2002)^{12} \\
\text { Reulen et al }(1997)^{13} \\
\text { Rostomily et al (1991) } \\
\text { Roux et al }(2001)^{15} \\
\text { Schiffbauer et al }(2002)^{16} \\
\text { Sobottka et al }(2002)^{17} \\
\text { Taylor et al }(1999)^{18} \\
\text { Wagner et al }(1997)^{19} \\
\text { Walsh et al }(1990)^{20} \\
\text { Whittle et al }(2003)^{21} \\
\text { Total }\end{array}$ & $\begin{array}{l}53(53) \\
5(2) \\
26(10) \\
11(7) \\
3 \\
8(4) \\
24 \\
40(25) \\
6(2) \\
65(18) \\
175(175) \\
24(24) \\
30 \\
5(4) \\
15(9) \\
183 \\
7(4) \\
121(21) \\
4 \\
4 \\
25 \\
834(358)\end{array}$ & $\begin{array}{l}0 \\
0 \\
1(4) \\
0 \\
0 \\
0 \\
0 \\
4(10) \\
0 \\
3(4.5) \\
10(6) \\
1(4) \\
4(13) \\
0 \\
0 \\
6(3) \\
0 \\
5(4.5) \\
0 \\
0 \\
1(4) \\
35(4.2)\end{array}$ \\
\hline
\end{tabular}

\section{Improvement of postoperative functional results}

Taking into account the fact that an LGG is usually revealed by seizures, in young patients leading an active socialprofessional life with a normal neurological examination or only a slight deficit, surgery should be considered on the sole condition that the risk of inducing a permanent deficit is low.

Clearly, in our experience, DES has significantly decreased the rate of sequelae (6.5\% in S2 v 17\% in S1), despite a higher number of surgeries performed within eloquent areas in S2. Indeed, the rest of the surgical methodology was the same in both series, and we did not use neurofunctional imaging data intraoperatively, integrated into an image-guided surgery system, even in S2.

Interestingly, our results are similar to those reported in the literature. In series where intraoperative electrical mapping was not used, the rate of sequelae ranged from $13 \%$ to $27.5 \%$, with a mean of $19 \%,{ }^{55-62}$ which is comparable to the results of our S1. In contrast, the rate of postoperative severe permanent deficit reported in the many studies describing the use of DES during surgery of LGG was quite similar at around 4\%, again close to our experience (S2). These comparisons are important since they show that DES represents a reliable and reproducible technique with consistent good results-whichever surgical team performs the resection (even in different countries). Our review covers 834 patients operated on for a glioma, including 358 LGGs, in 21 different neurosurgical departments distributed in nine countries (table 2). ${ }^{1-21}$

Furthermore, intraoperative electrical mapping excludes neither simultaneous electrophysiological monitoring by evoked potentials nor integration of preoperative neurofunctional imaging data in an image-guided system. ${ }^{15}{ }^{23}$ On the contrary, cortical DES may allow validation of positron emission tomography (PET), magnetoencephalography (MEG), functional (f)MRI, and even the recent method of fibre tracking by diffusion tensor imaging. ${ }^{63}$

\section{Improvement of the quality of resection}

Since intraoperative DES allows individual identification of the cortical and subcortical eloquent structures, it seems logical to perform a resection according to functional 
boundaries. Indeed, we suggest continuing the resection until after the functional structures are detected by DES, and not stopping before, in order to optimise the quality of resection without increasing the risk of inducing postoperative permanent deficit.

This surgical strategy based on the extensive use of DES during the resection, in our experience has significantly improved the quality of LGG removal. Only $37 \%$ of resections were defined as subtotal and $6 \%$ as total on postoperative MRI in series 1 , whereas $50.8 \%$ of resections were subtotal and $25.4 \%$ total in series 2-despite a higher number of surgeries within the critical areas-with a parallel decrease of the rate of sequelae.

Moreover, whereas extensive surgery is still controversial in LGG, the series' supporting the positive impact of such a surgical strategy argue that this benefit seems directly related to the quality of resection. ${ }^{1434}$ Our present oncological results provide the basis for strong arguments in this direction, since the rate of deaths was significantly decreased in cases of subtotal and total glioma removal, in comparison with partial removal. Interestingly, this observation was true for both our series (median follow up: S1 77 and S2 47 months) even though there were more patients with a complete or subtotal resection in S2.

\section{CONCLUSIONS}

The present work allows for the first time quantification of the contribution of intraoperative DES during LGG resection. Indeed, our results show that the use of this method leads to:

- extension of indications of LGG surgery within eloquent areas

- decrease of the risk of sequelae

- increase of the quality of tumour resection itself, with an impact on survival.

Thus, DES seems to represent a valuable adjunct to LGG surgery based on the premise that only radiologically total or subtotal resection has a positive impact on the natural history of these tumours.

\section{Authors' affiliations}

H Duffau, M Lopes, F Arthuis, A Bitar, J-P Sichez, R Van Effenterre,

L Capelle, Department of Neurosurgery, Hôpital de la Salpêtrière, Paris, France

Competing interests: none declared

\section{REFERENCES}

1 Berger MS, Deliganis AV, Dobbins JD, et al. The effect of extent of resection on recurrence in patients with low grade cerebral hemisphere gliomas. Cancer 1994;74:1784-91.

2 Cukiert A, Gronich G, Marino R Jr. Surgical approaches to tumors and epileptogenic zones close to Wernicke's area. Arq Neuropsiquiatr 1995:53:587-91.

3 Ebel H, Ebel M, Schillinger G, et al. Surgery of intrinsic cerebral neoplasms in eloquent areas under local anesthesia. Minim Invasive Neurosurg 2000;43: 192-6.

4 Ebeling U, Fischer M, Kothbauer K. Surgery of astrocytomas in the motor and premotor cortex under local anesthesia: report of 11 cases. Minim Invasive Neurosurg 1995;38:51-9.

5 Eisner W, Burtsher J, Bale R, et al. Use of neuronavigation and electrophysiology in surgery of subcortically located lesions in the sensorimotor strip. J Neurol Neurosurg Psychiatry 2002;72:378-81.

6 Fandino J, Kollias SS, Wieser HG, et al. Intraoperative validation of functional magnetic resonance imaging and cortical reorganization patterns in patients with brain tumors involving the primary motor cortex. J Neurosurg $1999 ; 91: 238-50$

7 Fukaya C, Katayama Y, Yoshino A, et al. Intraoperative wake-up procedure with propofol and laryngeal mask for optimal excision of brain tumor in eloquent areas. J Clin Neurosci $2001 ; 8: 253-5$.

8 Haglund $M$, Berger $M$, Shamseldin $M$, et al. Cortical localization of temporal lobe language sites in patients with gliomas. Neurosurgery 1994;34:567-74.
9 Krombach GA, Spetzger U, Rohde V, et al. Intraoperative localization of functional regions in the sensorimotor cortex by neuronavigation and cortical mapping. Comput Aided Surg 1998;32:64-73.

10 Meyer FB, Bates LM, Goerss BS, et al. Awake craniotomy for aggressive resection of primary gliomas located in eloquent brain. Mayo Clin Proc 2001;76:677-87.

11 Nikas DC, Bello L, Zamani AA, et al. Neurosurgical considerations in supratentorial low-grade gliomas: experience with 175 patients. Neurosurg Focus 1998:4. Article 4. Available at www.aans.org/education/journal/ neurosurgical/apr98/4-4-4.asp (accessed 22 November 2004).

12 Peraud A, Meschede M, Eisner W, et al. Surgical resection of grade II astrocytomas in the superior frontal gyrus. Neurosurgery 2002;50:966-77.

13 Reulen HJ, Schmid UD, Ilmberger J, et al. Tumor surgery of the speech cortex in local anesthesia. Neuropsychological and neurophysiological monitoring during operations in the dominant hemisphere. Nervenarzt 1997;68:813-24

14 Rostomily RC, Berger MS, Ojemann GA, et al. Postoperative deficits and functional recovery following removal of tumours involving the dominant hemisphere supplementary motor area. J Neurosurg 1991;75:62-8.

15 Roux FE, Ibarrola D, Tremoulet $M$, et al. Methodological and technical issues for integrating functional magnetic resonance imaging data in a neuronavigational system. Neurosurgery 2001;49:1145-57.

16 Schiffbaver $\mathbf{H}$, Berger MS, Ferrari $\mathrm{P}$, et al. Preoperative magnetic source imaging for brain tumor surgery: a quantitative comparison with intraoperative sensory and motor mapping. J Neurosurg 2002;97:1333-42.

17 Sobottka SB, Bredow J, Beuthien-Baumann B, et al. Comparison of functional brain PET images and intraoperative brain-mapping data using image-guided surgery. Comput Aided Surg 2002;7:317-25

18 Taylor MD, Bernstein M. Awake craniotomy with brain mapping as a routine surgical approach to treating patients with supratentorial intraaxial tumors: a prospective trial of 200 cases. J Neurosurg 1999;90:35-41.

19 Wagner W, Tschiltschke W, Niendorf WR, et al. Infrared-based neuronavigation and cortical motor stimulation in the management of centralregion tumors. Stereotact Funct Neurosurg 1997;68:112-16.

20 Walsh AR, Schmidt RH, Marsh HT. Cortical mapping and resection under local anesthetic as an aid to surgery of low and intermediate grade gliomas. Br J Neurosurg 1990;4:485-91.

21 Whittle IR, Borthwick S, Haq N. Brain dysfunction following "awake" craniotomy, brain mapping and resection of glioma. $\mathrm{Br} J$ Neurosurg 2003;17:130-7.

22 Hermann BP, Wyler AR. Comparative results of dominant temporal lobectomy under general of local anesthesia: language outcome. J Epilepsy 1988; 1:127-34.

23 Reithmeier T, Krammer M, Gumprecht $\mathrm{H}$, et al. Neuronavigation combined with electrophysiological monitoring for surgery of lesions in eloquent brain areas in 42 cases: a retrospective comparison of the neurological outcome and the quality of resection with a control group with similar lesions. Minim Invasive Neurosurg 2003;46:65-71.

24 Wood CC, Spencer DD, Allison D, et al. Localization of human sensorimotor cortex during surgery by cortical surface recording of somatosensory evoked potentials. J Neurosurg 1988;68:99-111.

25 Hermann BP, Wyler AR, Somes G, et al. Dysnomia after left anterior temporal lobectomy without functional mapping: frequency and correlates. Neurosurgery 1994;35:52-6.

26 Duffau H, Capelle L, Denvil D, et al. Usefulness of intraoperative electrical subcortical mapping during surgery for low-grade gliomas located within eloquent brain regions: functional results in a consecutive series of 103 patients. J Neurosurg 2003;98:764-78.

27 Karnofsky D, Burchenal JH. The clinical evaluation of chemotherapeutic agents in cancer. In: MacLeod CM, ed. Evaluation of Chemotherapeutic Agents. New York: Columbia University Press, 1949:191-205.

28 Mandonnet E, Delattre JY, Tanguy ML, et al. Continuous growth of mean tumor diameter in a subset of grade II gliomas. Ann Neurol 2003;53:524-8.

29 Duffau H, Capelle L, Denvil D, et al. Functional recovery after surgical resection of low-grade gliomas in eloquent brain: hypothesis of brain compensation. J Neurol Neurosurg Psychiatry 2003;74:901-7.

30 Duffau H, Capelle L, Sichez JP, et al. Intraoperative direct electrical stimulations of the central nervous system: the Salpêtrière experience with 60 patients. Acta Neurochir (Wien) 1999;141:1157-67.

31 Duffau H, Capelle L, Sichez N, et al. Intraoperative mapping of the subcortical language pathways using direct stimulations. An anatomo-functional study. Brain 2002;125:199-214.

32 Berger MS, Ojemann GA, Lettich E. Neurophysiological monitoring during astrocytoma surgery. Neurosurg Clin North Am 1990;1:65-70.

33 Berger MS, Ojemann GA. Intraoperative brain mapping techniques in neurooncology. Stereotactic Funct Neurosurg 1992;58:153-61.

34 Wiedemayer $\mathrm{H}$, Sandalcioglu IE, Armbruster W, et al. False negative findings in intraoperative SEP monitoring: analysis of 658 consecutive neurosurgical cases and review of published reports. J Neurol Neurosurg Psychiatry 2004;75:280-6.

35 Nimsky C, Ganslandt O, Fahlbusch R. Functional neuronavigation and intraoperative MRI. Adv Tech Stand Neurosurg 2004;29:229-63.

36 Blanshard HJ, Chung F, Manninen PH, et al. Awake craniotomy for removal of intracranial tumor: considerations for early discharge. Anesth Analg $2001 ; 92: 89-94$.

37 Danks RA, Rogers M, Aglio LS, et al. Patient tolerance of craniotomy performed with the patient under local anesthesia and monitored conscious sedation. Neurosurgery 1998;42:28-36.

38 Manninen PH, Tan TK. Postoperative nausea and vomiting after craniotomy for tumor surgery: a comparison between awake craniotomy and general anesthesia. J Clin Anesth 2002;14:279-83. 
39 Sarang A, Dinsmore J. Anesthesia for awake craniotomy-evolution of a technique that facilitates awake neurological testing. $\mathrm{Br} J$ Anaesth 2003;90:161-5.

40 Roux FE, Boulanouar K, Lotterie JA, et al. Language function magnetic resonance imaging in preoperative assessment of language areas: correlation with direct cortical stimulation. Neurosurgery 2003;52:1335-47.

41 Rutten GJ, Ramsey NF, van Rijen PC. Development of a functional magnetic resonance imaging protocol for intraoperative localization of critical temporoparietal language areas. Ann Neurol 2002;51:350-60.

42 Whittle IR. Surgery for gliomas. Curr Opin Neurol 2002;15:663-9.

43 Capelle L, Duffau H, Lopes M, et al. Supra-tentorial hemispheric WHO grade 2 gliomas in adults: a study of prognostic factors with special emphasis on the role of surgery. J Neuro-oncol 2002;4(suppl 1):S17, 69.

44 Keles GE, Liamborn KR, Berger MS. Low-grade hemispheric gliomas in adults: a critical review of extent of resection as a factor influencing outcome. J Neurosurg $2001 ; 95: 735-45$.

45 Schmidt MH, Berger MS, Lamborn KR, et al. Repeated operations for infiltrative low-grade gliomas without intervening therapy. J Neurosurg 2003;98: $1165-9$.

46 Fried I. Functional neuroimaging in presurgical localization of essential cortical processing zones. Adv Neurol 2000;83:297-303.

47 Duffau H, Capelle L, Lopes M, et al. The insular lobe: physiopathological and surgical considerations. Neurosurgery 2000;47:801-11.

48 Duffau H, Capelle L. Preferential brain locations of low-grade gliomas. Cancer 2004; 100:2622-6.

49 Duffau H, Capelle L, Denvil D, et al. The role of dominant premotor cortex in language: a study using intraoperative functional mapping in awake patients. Neurolmage 2003;20:1903-14.

50 Duffau $\mathrm{H}$, Bauchet $\mathrm{L}$, Lehéricy $\mathrm{S}$, et al. Functional compensation of the left dominant insula for language. NeuroReport 2001;12:2159-63.

51 Duffau H, Denvil D, Lopes M, et al. Intraoperative mapping of the cortical areas involved in multiplication and subtraction: an electrostimulation study in a patient with a left parietal glioma. I Neurol Neurosurg Psychiatry 2002;73:733-8.

52 Duffau H, Sichez JP, Lehéricy S. Intraoperative unmasking of brain redundant motor sites during resection of a precentral angioma: evidence using direct cortical stimulations. Ann Neurol 2000;47:132-5.

53 Duffau $\mathrm{H}$. Acute functional reorganization of the human motor cortex during resection of central lesions: a study using intraoperative brain mapping J Neurol Neurosurg Psychiatry 2001;70:506-13.

54 Duffau H, Denvil D, Capelle L. Long term reshaping of language, sensory, and motor maps after glioma resection: a new parameter to integrate in the surgical strategy. J Neurol Neurosurg Psychiatry 2002;72:511-16.

55 Apuzzo ML. Brain surgery. Complication avoidance and management. New York: Churchill Livingstone, 1993;1:379-90.

56 Brell M, Ibanez J, Caral L, et al. Factors influencing surgical complications of intra-axial brain tumours. Acta Neurochir (Wien), 2000;142:739-50.

57 Cabantog AM, Berstein M. Complications of first craniotomy for intra-axial brain tumour. Can J Neurol Sci 1994;21:213-18.

58 Cedzich C, Taniguchi M, Schäfer S, et al. Somatosensory evoked potential phase reversal and direct motor cortex stimulation during surgery in and around the central region. Technical application. Neurosurgery 1996;38:962-71

59 Fadul C, Wood J, Thaler H, et al. Morbidity and mortality of craniotomy for excision of supratentorial gliomas. Neurology 1988;38:1374-9.

60 Sawaya R, Hammoud M, Schoppa D, et al. Neurological outcomes in a modern series of 400 craniotomies for treatment of parenchymal tumors. Neurosurgery 1998;42:1044-56

61 Tandon P, Mahapatra AK, Khosla A. Operations on gliomas involving speech centres. Acta Neurochir Suppl (Wien) 1993;56:67-71.

62 Vives KP, Piepmeier JM. Complications and expected outcome of glioma surgery. J Neurooncol 1999;42:289-302.

63 Holodny Al, Schwartz TH, Ollenschleger M, et al. Tumor involvement of the corticospinal tract: diffusion magnetic resonance tractography with intraoperative correlation. Case illustration. J Neurosurg 2001;95:1082. 